\title{
MENUMBUHKAN MINAT BERWIRAUSAHA MELALUI PELATIHAN PERANCANGAN MODEL BISNIS KANVAS
}

\author{
Larisa Yohanna, Endang Sondari \\ Pendidikan Bahasa Inggris, Fakultas Bahasa dan Seni, \\ Universitas Indraprasta PGRI \\ larisayohanna@gmail.com,endang_sondari@yahoo.com
}

\begin{abstract}
Abstrak
Keberadaan Pendidik sebuah bangsa merupakan faktor yang harus diperhatikan dengan serius oleh semua pihak yang berkepentingan, yang memiliki kepedulian bukan hanya terhadap bidang pendidikan, namun juga kepedulian terhadap kesejahteraan masyarakat. Pemberian keterampilan melalui program Life Skill kepada masyarakat belum dapat dimanfaatkan secara optimal untuk meningkatkan kemandirian dan kesejahteraan. Pengenalan model bisnis kanvas dapat bersinergi dengan Life Skill yang mereka dapatkan. Kegiatan pelatihan perancangan model bisnis kanvas bertujuan agar minat berwirausaha masyarakat tumbuh seiring dengan bertambahnya pemahaman mereka bahwa memulai usaha sangatlah mudah, dengan perancangan model bisnis yang simpel namun terarah. Hasil yang diperoleh dalam kegiatan pengabdian kepada masyarakat adalah sebagai berikut : 1) Sebelum diadakan pelaksanaan kegiatan, minat berwirausaha peserta terindikasi rendah, hanya 8,3\% yang berminat untuk berwirausaha, dan 2) Adanya peningkatan minat peserta untuk berwirausaha setelah pemberian materi motivasi dan pengenalan perancangan model bisnis kanvas, dengan tingkat minat berwirausaha sebesar $64,2 \%$.
\end{abstract}

Kata Kunci : Perancangan Model, Model Bisnis Kanvas, Minat Berwirausaha

\begin{abstract}
The existence of a nation's Educator is a factor that must be taken seriously by all interested parties, who have concern not only for the education sector, but also for the concern for the welfare of the community. Giving skills through the Life Skill program to the community cannot be used optimally to increase their independence and welfare. The introduction of the business model canvas can synergize with the Life Skills they have gotten. The canvas business model design training activities aim to make community entrepreneurship interest grow along with their increasing understanding that starting a business is very easy, with the simple and directed design of business model. The results obtained in the community service activities are as follows: 1) Prior to the implementation of activities, interest in entrepreneurship was indicated as low, only $8.3 \%$ were interested in entrepreneurship, and 2) There was an increase in participants' interest in entrepreneurship after giving motivation and introduction designing a business mode canvas, with a level of entrepreneurial interest of $64.2 \%$.
\end{abstract}

Keywords: Model Design, Business Model Canvas, Entrepreneurial Interest

\section{PENDAHULUAN}

Kota Administarasi Jakarta Utara yang memiliki populasi penduduk sekitar 1.173.935 orang dengan penduduk miskin berkisar pada angka 205.959 orang (Sumber BPS: 2006). Hal ini memperlihatkan bagaimana kondisi faktual menyatakan jelas masih 
banyak penduduk miskin yang membutuhkan perhatian. Secara sosial masyarakat marjinal banyak yang tinggal di lingkungan sekitar rel kereta api, pasar, tanah garapan dan rumah tinggal sempit yang memiliki tingkat kerawanan cukup tinggi. Begitu juga secara ekonomi umumnya masyarakat adalah masyarakat yang memiliki ekonomi lemah dengan tingkat penghasilan rendah yang aktivitas sehari-harinya sebagai buruh, pedagang kecil dan pengepul barang bekas.

Berawal dari kepedulian terhadap rendahnya tingkat pendidikan dan kesejahteraan masyarakat di Kelurahan Pademangan, maka PKBM Negeri 04 Pademangan, mencoba membangun kesadaran masyarakat sekitar akan pentingnya pendidikan dengan membuka kesempatan untuk meraih pendidikan seluas-luasnya serta menumbuhkan jiwa berwirausaha dengan memberikan life skill, entrepreneur knowledge dan skill yang memadai. Kelak mereka diharapkan dapat memiliki masa depan yang lebih cerah dan sejahtera dengan pendidikan dan keterampilan yang mereka miliki.

Menteri PPN/Kepala Bappenas, Bambang Brodjonegoro menjelaskan bahwa tingkat kemiskinan tahun depan diasumsikan 9,5 persen-10,5 persen. Di 2016, targetnya 10,5 persen tapi realisasinya 10,6 persen karena masalah pertumbuhan ekonomi tidak setinggi yang diharapkan. Daya serap tenaga kerja juga lebih rendah, pertumbuhan ekonomi tidak tinggi seperti yang diharapkan, investasi tidak besar dan yang masuk padat modal tidak lagi padat karya sehingga kemiskinan turunnya melambat (Liputan6.com: 2017). Sehubungan dengan pernyataan tersebut, menjadi sebuah $P R$ besar bagi PKBM Pademangan untuk dipecahkan agar specific life skills (tata boga, komputer, menjahit dan lainnya) yang telah diberikan dapat memberikan manfaat di masa depan bagi masyarakat yang sudah belajar.

Mitra sadar bahwa kelulusan pendidikan dengan berbekal life skill dan entrepreneurship knowledge sangatlah penting bagi masa depan mereka agar dapat memperbaiki ekonomi keluarga dan mandiri. Oleh karena itu kegiatan pengabdian kepada masyarakat ini bertujuan untuk : 1) Membuka pola pikir masyarakat untuk berwirausaha sehingga terciptanya kemandirian, 2) Memberi pemahaman kepada masyarakat bahwa memulai usaha dengan perencanaan yang matang sangatlah simple, 3) Membekali peserta dalam memulai usaha dengan perancangan model bisnis kanvas, dan 4) Menumbuhkan kesadaran dan minat berwirausaha masyarakat agar mereka tidak terkurung dalam kemiskinan dan kelak dapat hidup sejahtera.

Luaran dari kegiatan pengabdian masyarakat ini adalah tumbuhnya minat berwirausaha masyarakat, seiring dengan bertambahnya pemahaman mereka bahwa memulai usaha sangatlah mudah dengan perancangan suatu model bisnis yang simpel namun terarah. Dengan menggunakan angket dapat terlihat adanya minat mereka untuk berwirausaha.

\section{METODE PELAKSANAAN}

Dalam kegiatan ini, pelaksanaan dilakukan selama 2 (dua) hari pada tanggal 20-21 Januari 2017 dengan tahapan-tahapan yang dilaksanakan yaitu :

1. Tahap awal.

Setelah Sambutan oleh Kepala Sekolah, tim pelaksana memberikan motivasi kewirausahaan dengan diawali pemberian angket mengenai kondisi warga belajar apakah mereka sudah ada yang berwirausaha atau berdagang, apakah mereka berniat untuk berwirausaha (bagi yang belum) dan alasan mereka terhadap ketidak-minatan mereka untuk berwirausaha. Kemudian, pemberian motivasi yang bertujuan untuk 
menumbuhkan kesadaran dan minat peserta untuk berwirausaha. Materi pemberian motivasi, selain berdasarkan kepada materi yang telah disiapkan, materi juga disesuaikan dengan hasil angket yang telah dikumpulkan dengan melihat alasan yang menyebabkan mereka tidak berminat untuk berwirausaha.

2. Tahap Pengenalan

Pengenalan perancangan model bisnis kanvas dilakukan secara mendalam. Selama ini masyarakat enggan untuk berwirausaha karena selain modal menjadi faktor utama bagi mereka untuk memulai usaha, mereka juga menghadapi suatu kebingungan bagaimana memulai suatu usaha dan apa yang harus mereka lakukan diawal. Hal ini yang menyebabkan mereka tidak berminat untuk berwirausaha dan beranggapan bahwa memulai usaha sangatlah kompleks dan beresiko tinggi untuk merugi. Oleh karena itu dengan pengenalan perancangan model bisnis kanvas sebagai salah satu langkah memulai suatu usaha yang diharapkan dapat menumbuhkan minat berwirausaha .

\section{Tahap Pelatihan}

Membuka bisnis memerlukan keberanian namun bisnis juga memerlukan perhitungan yang matang, sehingga resiko apapun yang muncul dapat dikelola dengan baik. Salah satu cara termudah menyiapkan rencana bisnis adalah dengan membuat model bisnis. Dengan perancangan ini dapat memudahkan pemula usaha dalam memetakan arah usaha dan meminimalisir resiko kegagalan. Dalam buku "Business Model Generation" (Osterwalder \& Pigneur : 2010) Model Bisnis Canvas adalah model bisnis yg terdiri dari 9 blok area aktivitas bisnis, yang memiliki tujuan memetakan strategi untuk membangun bisnis yang kuat, bisa memenangkan persaingan dan sukses dalam jangka panjang. Bisnis Model Canvas ini memiliki ciri khas dengan 9 blok model yang jika disatukan akan menjadi satu kesatuan bisnis:
a. Customers Segment
b. Value Proposition
c. Customer Relationship
d. Channel
e. Revenue Stream
f. Key Resource
g. Key Activities
h. Key Partnership
i. Cost Structure

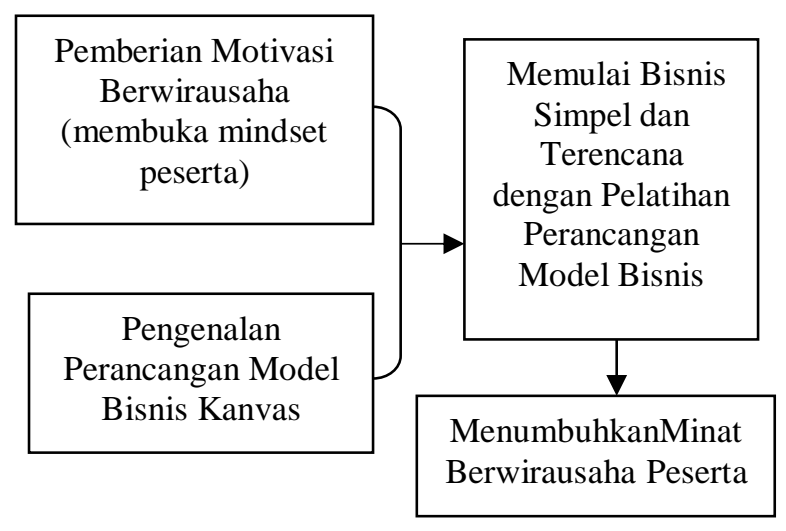

Gambar 1 Alur IPTEK Transfer ke Mitra 
Keterampilan Masyarakat Menjahit, memasak dan lainnya) akan menjadi aset masa depan jika dimanfaatkan dengan baik. Kontribusi kegiatan pengabdian kepada masyarakat dengan memberikan motivasi (membuka mindset pentingnya berwirausaha) dan pengenalan model bisnis kanvas, diharapkan dapat menumbuhkan minat berwirausaha peserta. Selama ini peserta pastinya sangat awam dan menganggap bahwa memulai suatu bisnis sangat sulit dan tidak ada pengetahuan yang dapat menunjang.

\section{HASIL DAN PEMBAHASAN}

Pelaksanaan kegiatan ini dihadiri oleh peserta wanita sebanyak $47 \%$ dan sisanya laki-laki, dengan usia dominan berkisar 17 tahun. Peserta yang hadir yang telah berwirusaha/berdagang hanyalah 29\%. Dari 12 peserta yang belum memiliki usaha/berdagang hanya $8.3 \%$ yang berminat untuk berwirausaha kelak. Hal ini dikarenakan berbagai alasan antara lain : tidak memiliki modal, takut rugi, dan tidak memiliki bakat (masing-masing alasan sebanyak 25\%), tidak memiliki skill dan pengalaman (masing-masing alasan sebesar 12,5\%). Penyampaian materi disesuaikan dengan kondisi apa yang menjadi keyakinan peserta pada saat itu kenapa mereka tidak berminat untuk berwirausaha sehingga lebih cenderung menjadi karyawan/buruh kelak (berdasarkan angket yang telah dibagikan sebelum pemaparan materi motivasi).

Berdasarkan hasil analisis angket yang telah dibagikan kepada 17 peserta (setelah pemaparan dan latihan perancangan model bisnis kanvas) skor total adalah 2438 , dikategorikan tingkat minat berwirausaha peserta adalah sedang atau sebesar 64,16\%.

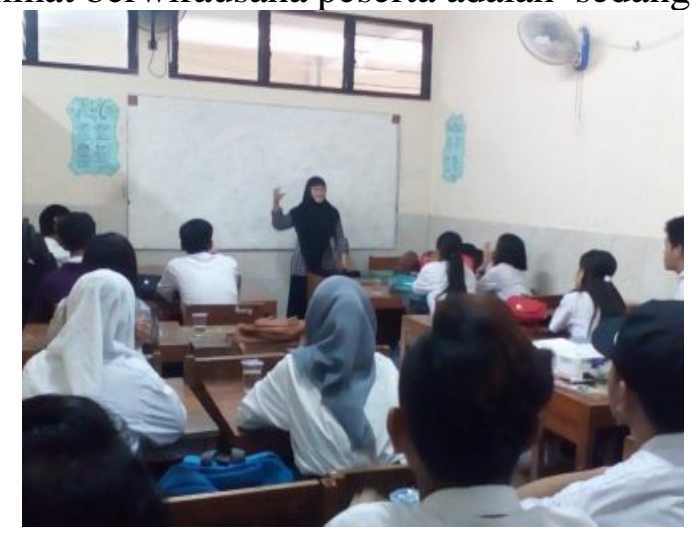

Gambar 2 Pemaparan Motivasi Kewirausahaan (Sumber : Dokumentasi Pribadi)

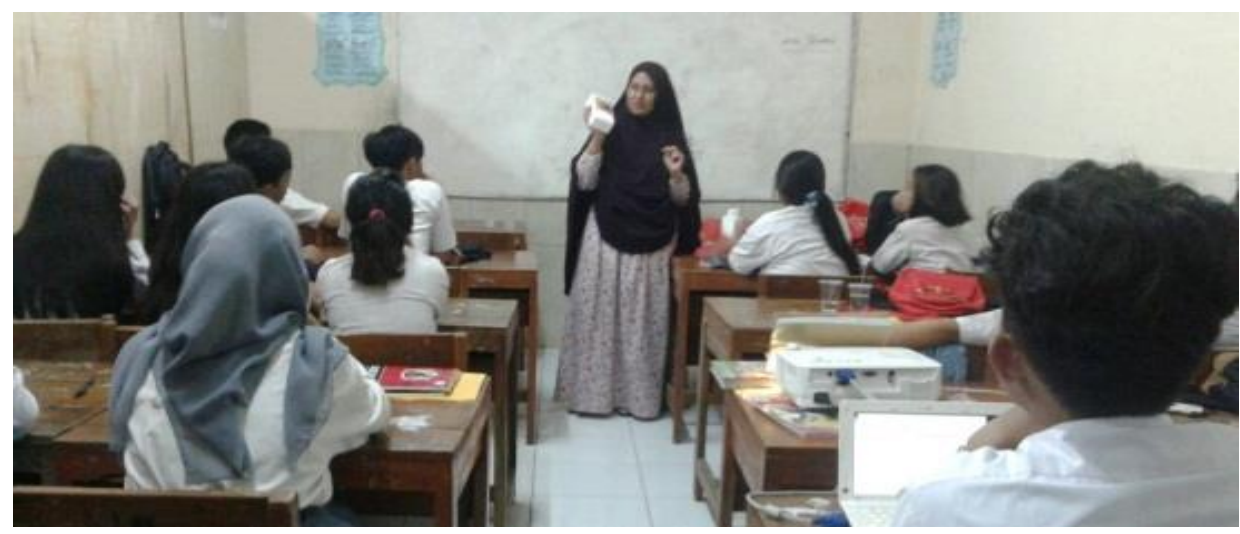

Gambar 3 Pemaparan Model Bisnis Kanvas

(Sumber : Dokumentasi Pribadi) 


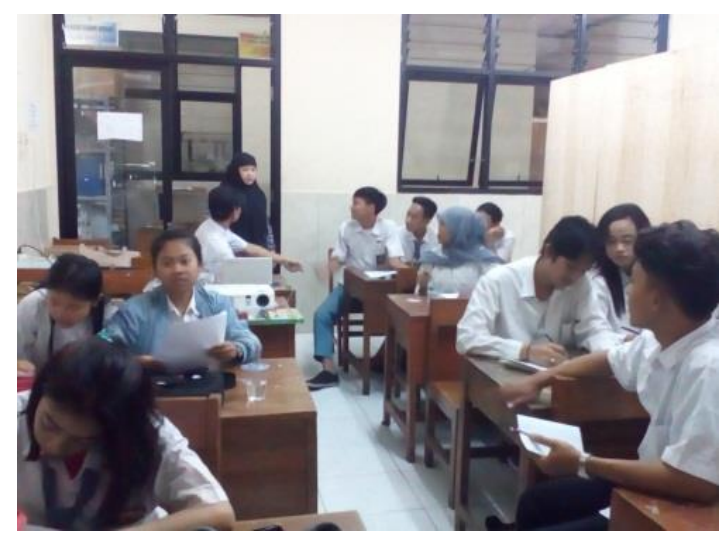

Gambar 4 Diskusi Kelompok Peserta (Sumber : Dokumentasi Pribadi)

\section{SIMPULAN}

Secara umum kegiatan pelaksanaan pengabdian kepada masyarakat dikatakan berhasil karena :

1. Adanya peningkatan minat peserta untuk berwirausaha dengan nilai sebesar $64,2 \%$ yang awalnya hanya $8,3 \%$.

2. Pengenalan model bisnis kanvas berhasil tersampaikan walaupun dalam proses latihannya hanya $25 \%$ yang telah selesai menyelesaikan layoutnya.

3. Adanya persiapan yang lebih mendalam untuk penyampaian materi oleh tim pelaksana untuk model bisnis kanvas karena mayoritas background pendidikan peserta adalah usia terlambat sekolah (17 tahun s.d. 22 tahun).

4. Adanya tambahan waktu pertemuan dari mitra sehingga penditribusian ilmu pengetahuan dan keterampilan dalam berwirausaha bisa lebih maksimal.

5. Mitra dapat menambahkan mata pelajaran kewirausahaan dalam kurikulum pembelajaran.

\section{UCAPAN TERIMA KASIH}

Untuk yang pertama, saya ucapkan terima kasih kepada LP2M Universitas Indraprasta PGRI yang telah mendukung kegiatan pengabdian masyarakat ini, dan Ibu Suratminah, S.Pd., M.Si., Kepala Sekolah PKBM Negeri 04 Pademangan, Jakarta Utara beserta para staf yang telah mendukung kegiatan ini sehingga berjalan lancar.

\section{DAFTAR PUSTAKA}

Andi. (2015). 20 Pengertian Kewirausahaan Menurut Para Ahli Ekonomi. http:// www. orangbejo.com/2015/12/20-pengertian- kewirausahaan-menurut.html. Diakses 15 Desember 2017.

Anwar. (2004). Pendidikan Kecakapan Hidup (Life Skill Education). Bandung: Alfabeta.

Brodjonegoro. (2017). Kemiskinan dan Pengangguran. http: //bisnis.liputan6 . com/read/2590110/ini-target-angka-kemiskinan-dan-pengangguran-ri-di-2017.

Diakses 9 Januari 2018. 
Depdiknas. (2002). Pengembangan Pelaksanaan Broad-Based Education, High-Based Education, dan Life Skills di SMU. Jakarta: Depdiknas.

IOWA State University. (2003). Incorporating Developmentally Appropriate Learning Opportunities to Assess Impact of Life Skill Development. http://www.extension.iastate.edu/4H/lifeskills. Diakses 15 Desember 2017.

Ostewalder, A. and Pigneur, Y. (2010). Business Model Generation. New Jersey: John Wiley \& Sons, Inc. 